\title{
The Teaching Reform of Analytical Chemistry under the Background of Massive Open Online Courses
}

\author{
Yongpeng $\mathrm{XIE}^{1, \mathrm{a}}$ Yingge Yang ${ }^{2, b}$ \\ 1 College of Education Science and Technology , Xuzhou Institute of Technology , Xuzhou, \\ Jiangsu, 221006, China \\ 2 Department of Bioengineering, Xuzhou Vocational college of Bioengineering, Xuzhou, Jiangsu, \\ 221006, China \\ aemail: xieyongpeng@163.com bemail:ygyang_1982@163.com
}

Keywords: MOOCs; Massive open online courses; analytical chemistry; teaching reform

\begin{abstract}
MOOCs inherit the concept of open and shared knowledge of OER and achieve the global share of quality education resources successfully and efficiently. They are a breakthrough innovation for learning ways and methods. The disadvantages of the traditional teaching mode of analytical chemistry is mainly reflected in two aspects. On the one hand, the traditional teaching method is too conservative. On the other hand, quality teaching resources is insufficient and teaching content is disconnected from times. MOOCs bring infinite vitality and potential to the teaching reform of analytical chemistry. There are three sides to improve analytical chemistry teaching under the background of MOOCs. First, teachers and students should change the role of themselves and improving the students' initiative in learning. Secondly, teachers should reconstruct the knowledge structure of analytical chemistry. Finally, teachers should guide the autonomous learning and autonomous experiment design in virtue of the blended learning mode.
\end{abstract}

\section{Introduction}

Throughout history, educators and researchers have always been intrigued with the potential of technology to help transform education and improve student learning (Hew \& Brush, 2007). One such technology is the use of the Internet to deliver courses; typically known as e-learning. With the continuous development of information technology, department of education promulgated a series of projects, for example, project of teaching quality and teaching reform, project of professional teaching resources construction, open courses of quality video, sharing courses of excellent resource and so on. Under this background, the construction of the network course, which is supported by information technology, is developing rapidly. The Massive Open Online Courses (MOOCs) are widely used in higher education courses. At present, many colleges and universities have already started a blended teaching mode reform which is the combination of online education and line education. However, MOOCs are not a simple movement of the courses to the Internet. Therefore, it is necessary to explore how to integrate the MOOCs and traditional experiment teaching of analytical chemistry. Effective use of online learning platform to assist the analytical chemistry experiment teaching can not only give full play to the students' learning initiative, enthusiasm and creativity, but also play the guiding role of teachers in the material chemistry experiment teaching. So, MOOCs can fundamentally change teachers' teaching methods and students' learning style, and improve the students' lifelong learning ability finally. 


\section{The origin and development of MOOCs}

The concept of open education resources is open and shared. Its development begins with the Open education resources (OCW) movement of MIT. As early as 2002, MIT put a lot of courses online for people to study free of charge. Subsequently, with the development of the open education resources (OER), more and more colleges and educational institutions shared the quality education resources. Massive open online courses (MOOCs), which are open access and scalable online educational courses that can be used by anyone worldwide, have become a trend since the first MOOC, Connectivism and Connective Knowledge (CCK08), was offered by the University of Manitoba in 2008 (Fini, 2009).In 2012, the field of open educational resources has appeared a new round of high tide. Internet companies whose core is online courses have emerged and obtained the rapid development. Udacity, Coursera, edX, udemy and so on, their curriculum are free of charge and of high quality and provide the learner a wide range of online support, including course tasks assignment, learning assessment, interaction between teacher and students. They provide academic certificate for the learners of completing the course successfully. This kind of service has been widely welcomed. People named the emerging massive open online education mode MOOCs and the 2012 called the year of the MOOCs.

MOOCs inherit the concept of open and shared knowledge of OER. It achieves the global share of quality education resources successfully and efficiently. It is a breakthrough innovation for learning ways and methods. At present, education institutions around the world have input into massive open online courses. A number of network courses have sprouted. After the projects of the national excellent courses and the university network open class, colleges and universities in our country also pay close attention to the development of MOOCs. Peking University has launched the MOOCs program. Shanghai university curriculum alliance also realized the high-quality resources sharing between universities in Shanghai and can obtain credit accredited by schools. With the rise of the MOOCs, many universities and educational institution in our country are vigorously constructing the course sharing platform.

\section{The outstanding advantage of MOOCs}

The success of Khan Academy caused the attention and vision of the whole society to the online education. As a new product of the depth of integration of information technology and higher education, MOOCs can be said to be "upgraded version of Khan academy". Its progress is reflected in the cooperation with the outstanding teachers in the famous universities, agglomeration and the production of high-quality curriculum. MOOCs move the whole teaching process to the network in order to classroom reappearance. MOOCs ensure learners can learn these videos conveniently and quickly using the network at any time and in any place. In most cases participants sign up for MOOCs free of charge and in some cases for a small or minimal fee to obtain a completion certificate. Others believe that MOOCs can increase an institution's prestige, or as a tool for universities to market themselves to potential students, faculty, and donors(Rice, 2013).

MOOCs present outstanding advantage of a new kind of teaching and learning. First of all, MOOCs highlight the center of the learner. The ultimate goal of the teaching is for the students' learning. MOOCs reflect the interaction between teachers and students and the students' learning experience, and the essence of "learning" is back. The communication and the thought collision between the teachers and the students reflect more understanding to the knowledge. The study is the students' construction of knowledge and the depth of knowledge in the collision with the teacher, and it is no longer the passive acceptance of knowledge. Second, MOOCs expand the time and space of the learning. With the popularity of mobile technology and the development of mobile terminal, especially the rapid development of Internet technology, Learning activity of learners no longer subject to the restriction of time and place. And then the students can be met the personalized learning needs rather than confined to the traditional classroom. For learners in the Internet era, using MOOCs to learn will become the main way to study for everyone, and will become an 
important way of learning. Basically, any individual with an Internet connection can join MOOCs, to access the available resources, interact with other students, reflect and share what they have learned with others (Kop, 2011). Third, MOOCs created an immersion and social learning environment. MOOCs provide free access to high-quality learning materials, offered by elite universities. They are conceptualized as online learning environments in which participants worldwide can create, research, and share open educational resources. Facebook, Wiki, Blog, twitter and others provide free exchange platform for learners and create learning community oriented vocational demand and professional promotion in order to meet learners' personalized needs based on improving professional quality and the pursuit of knowledge.

Compared with the traditional classroom teaching mode, MOOCs also has inherent defects. On the one hand, the main communication mode of MOOCs learning is man-machine conversation, which is lack of instant interaction between teachers and students, furthermore, lack of the face-to-face communication with teachers and peers. On the other hand, the main learning style of MOOCs is learning without limits. So, Second is free MOOCs way of learning and put forward higher requirements on learners' Autonomy of learning and self-discipline. In other words, how to solve sustainability issues of the learning interest and learning process? These inner defects should be avoided in the course of analytical chemistry teaching.

\section{The disadvantages of the traditional teaching mode of analytical chemistry}

\section{The traditional teaching method is too conservative}

Traditional analytical chemistry teaching follows the conservative way. It can be summed up as: "emphasis on theory, ignore practice; pay attention to knowledge, neglect wisdom." In order to complete the teaching plan, the teacher took the understanding and thought of the course to the students mechanically. There is no thinking space for students. Learners just passively accept the disposable resources in the classroom. The students lack motivation and has been used to receiving chemical knowledge passively. Obviously, these traditional models hinder the students' personality and kills the students' innovative spirit and practical ability. At the same time, laboratory instruments and equipment has not been updated for many years in most universities. Furthermore, hours of analytical chemistry are limited. The main form of experiment class is routine verification experiment. There are little research experiments and comprehensive experiment, which makes students feel no challenging and lack passion to the experiment. Undoubtedly, this suppresses the students' ability of innovation and development severely.

\section{Quality teaching resources is insufficient, Teaching content is disconnected from times}

The course characteristic of analytical chemistry is various formula, careful logic, delicate calculation. For example, in the experiment of coordination titration, There are many balance such as acid-base balance, coordination balance and so on. It requires learners to be able to find out the main controlling factors in the complex reaction system, then carry out mathematical calculation and judgment finely and accurately in accordance with the requirements of the error. All of these have a huge challenge to the learners. In the case of the same teaching content and even some expansion, it has only a relatively limited teaching hours. One of the main ways to solve the above problems is using the teaching resources video to assist teaching. However, the teaching resources used in the course of the teacher is too outdated. Some teachers want to search for higher quality teaching resources, but nowhere to find.

In addition, the development of science and technology is changing each day rapidly. There is mutual penetration and the cross of each other between disciplines. The research system taking the interdisciplinary research as the main body is mainly responsible for the high level scientific research and the training task of the high-level talented person. The essence of interdisciplinary is subject crossing. Subject crossing is the source of innovative ideas. There are almost no changes in the analytical chemistry syllabus in many colleges. Teaching content is disconnected from times. obviously, the analytical chemistry teaching content has been seriously out of line with the new technical requirements of the present rapid development. 


\section{The teaching reform of analytical chemistry under the background of MOOCs}

\section{Changing the role of teachers and students and improving the students' initiative in learning}

In the teaching process of traditional analytical chemistry experiment, teachers generally explain the experiment principle, experiment procedure and sector to make mistakes easily, and then demonstrate to students. Students step by step to finish the experiment. This teaching method is mainly based on the teacher, and the students are the assistant. In the context of the MOOCs, We should promote the teacher's leading role, and play the students' main role in the analytical chemistry experiment teaching. Before the experiment, students are required to understand the experiment principle and content with the aid of high quality teaching resources in MOOCs. thinking, let the students to prepare the experiment with experiment preparation questions. Students inquire and watch the corresponding online video of MOOCs; When students go into the lab, teachers should check students' preview situation and put forward the emphasis and difficulty in the teaching and matters needing attention. Taking the acid-base titration experiment for example, teacher suggests the students have a slow and diffuse titration before reaching the destination. It is possible that half drops will reach the destination. sometimes the color of experiment titration end point is very shallow and can not judge the end easily. Teacher should remind the students to think of a solution, such as contrast with the blank experiment, control of indicative dose and so on. When students encounter problems again, they will have their own groping to find out the scheme to solve the problem. Obviously, it trains the students' ability to solve problems independently. During the course of the experiment, teachers should guide the students to find out the reasons of the problem according to the problems that students encounter by themselves and inspire students to think about the solution to the problem. In the course of analytical chemistry theory teaching, the teacher plays the role of the guide, the students are the subject of study. Teachers should strive to make classroom teaching interesting and take full advantage of the video teaching resources of MOOCs platform. MOOCs bring infinite vitality and potential to the teaching reform of analytical chemistry.

\section{Reconstruction of the knowledge structure of analytical chemistry}

Under the background of MOOCs, the teacher can use the flipped classroom teaching mode. The students use online video resources to complete the knowledge learning before the classroom teaching and complete the transfer and deepening of knowledge in the classroom with teacher. MOOCs eased the limitation of class time to a certain extent. MOOCs not only make the teacher have sufficient time to carry out rich and colorful teaching activities in classroom teaching, but also make the teacher reconstruct the knowledge structure of analytical chemistry so as to cultivate students' innovation ability and the ability of independent research. The teacher can readjust the contents of the analytical chemistry course, for example, four large titration and so on. According to the curriculum system, teachers adjust the structure and content of the curriculum, and Supplement, adjust, revise, the contents of the analytical chemistry course appropriately, forming a relatively complete and independent system of knowledge in order to apply autonomous learning. For example, teacher can add topics about four titration integration in the overall arrangement of content and introduce the concept of ionic strength in coordination titration. In addition, teacher can expound excel software applications for the complex calculation.

Teachers should gradually establish the concept of organizing classroom under the condition of the network and constructing the tree of knowledge system of analytical chemistry easy to spread. Teacher can segment course content according to the integrity of the knowledge and the intrinsic relationship between knowledge. All the knowledge points of analytical chemistry are divided into blocks, grouping, clustering. Finally, the relationship between the knowledge points is expressed intuitively with concept map and made explanations and descriptions. These can make students recognize the difficulties and focus, explore the connotation and denotation of knowledge structure. It is necessary for students to construct the meaning and to design the multi - thread classroom platform. For example, coordination titration includes a lot of knowledge points. Such as the transformation between dissociation constant and accumulation constant, side reaction of EDTA 
and the calculation of side reaction coefficient, side reaction of metal ions and the calculation of side reaction coefficient, calculation of complex condition formation constant, titration curve drawing and calculation of measurement points, the jump range of the coordination titration, the principle and choice of metal indicator, derivation and Application of end point error formula, criterion for direct and accurate titration of single metal ions, criterion for separate titration of multiple metal ions and so on. There are no order between some knowledge points in the learning process and students can arrange learning sequence flexibly. However, some are sequential and some modules are related to each other. These relationships need to be explained to the students.

\section{Guide the autonomous learning and autonomous experiment design in virtue of the blended learning mode}

The introduction of MOOCs is bound to cause the new changes in the analytical chemistry teaching organization. Students need to conduct the blended learning model consist of the autonomous learning, the teacher education and the cooperative learning with the help of the open educational resources. Teacher should advocate students use MOOCs resources for autonomous learning. However, this does not mean that the liberation of the teacher. In contrast, the burden of teaching teachers is more heavily. Teachers need to design more inclusive and open curriculum and training programs. Classroom teaching organization and teaching process, students' learning process and performance management will be more flexible. Classroom teaching resource construction of institute will produce change correspondingly. The institute should introduce MOOCs, establish the innovation curriculum based on knowledge fragments and multi-dimensional cross reference MOOCs resources in order to support the reform of teaching method with information technology. The institute will change its way of teaching service to the outside through joining the analytical chemistry MOOCs course alliance or university shared curriculum alliance. The institute can provide open education service to students in other schools and the society based on the MOOCs platform. In addition, in order to solve the problems that students encounter in the process of autonomous learning, teachers can allow students to freely combined into a group. Each team carried out the review of the literature, the experiment design and verification ,the final summary discussion and other activities under the guidance of the teacher. The process of the experiment report summary is a very important part. Students will often write verification experiment report or comprehensive experiment report, which requires experiment teachers to conduct scientific research training to students in order to enable students to write experiment reports like research papers. This is essential for developing students' innovation ability. If the process is properly organized, It will inspire students' learning motivation, enhance the students understanding, thinking, judgment, text organization, expression ability and innovation ability, especially the comprehensive ability to analyze the problem and solve the problem.

\section{Conclusions}

Analytical chemistry teaching mode integrated with the MOOCs can be developed as the characteristic teaching mode. The students generally reflect that the teaching reform characterized by autonomous inquiry and open choice is more interesting, challenging and creative. It greatly inspired students' autonomous learning enthusiasm and initiative, as well as Students master the basic methods for scientific research. Comprehensive experiment is beneficial to combine the chemical profession basic knowledge and the experiment skill organically. Thus, students form a more complete and in-depth cognition. In addition, students have infinite potential. There are often some unexpected results in the experiments, which in turn urge teachers to do more in-depth exploration.

MOOCs are a new thing. It can make more people to get quality education resources with low cost. The birth and development of MOOCs can make up for the shortage of the traditional education mode in a certain degree. Educators should strengthen the research on the application of MOOCs in Higher Education in order to promote the fusion with the traditional way of education. 
The two ways complement each other. This new way of learning will certainly bring new energy to the analytical chemistry teaching.

\section{References}

[1]Hew, K. F., \& Brush, T. (2007). Integrating technology into K-12 teaching: Current knowledge gaps and recommendations for future research. Educational Technology Research and Development, 55(3), 223-252.

[2]Fini, A. (2009). The technological dimension of a massive open online course: The case of the CCK08 course tools. The International Review of Research in Open and Distance Learning, 10(5).

[3]Rice, J. (2013). What I learned in MOOC. College Composition and Communication, 64(4), 695-703.

[4]Kop, R. (2011). The challenges to connectivist learning on open online networks: Learning experiences during a massive open online course. International Review of Research in Open and Distance Learning, 12(3), 19-38. 